Bull. Mater. Sci., Vol. 21, No. 4, August 1998, pp. 355-361. (O Indian Academy of Sciences.

\title{
Chemically modified clays as recyclable adsorbents for iodine
}

\author{
B S KRISHNA, S SELVARAJ, B V MOHAN ${ }^{\ddagger}$, D S R MURTY ${ }^{\ddagger}$ and B S JAI PRAKASH* \\ Department of Chemistry, Bangalore Institute of Technology, KR Road, Bangalore 560 004, India \\ ${ }^{\dagger}$ Ceramic Technological Institute, BHEL, Bangalore 560012 , India \\ ‡Chemical Laboratory, Atomic Minerals Division, DAE, Nagarabhavi, Bangalore 560072 , India
}

MS received 20 April 1998; revised 12 May 1998

\begin{abstract}
The adsorption behaviour of iodine on chemically modified swelling type of clays has been studied. Chemical modification was brought about by interacting the clay with surfactants such as tween-80 and polyethylene glycol. Adsorption of iodine was found to increase by several orders of magnitude on chemical modification which remained constant between $\mathrm{pH} 1$ and 10. The adsorption isotherms were non-linear and fitted the Freundlich equation for swelling clays. Scatchard analysis of the data indicated minimum two types of active sites with the tween-80 modified clay and one type with the polyethylene glycol modified one. The iodine sorbed on the surface was found to get desorbed almost completely on leaching with water. Modification of the clay surface with surfactant thus offers a method of designing a recyclable adsorbent for iodine.
\end{abstract}

Keywords. Montmorillonite; surfactant; iodine adsorption; surface modification; recyclable adsorbent.

\section{Introduction}

The importance of clay minerals in many process industries has led to their extensive studies in the past. There is a large amount of literature concerning the adsorption of various pollutants by clays but their effective removal from aqueous systems is limited because of the hydrophilic nature of the clays (Mortland 1970, 1986; Theng 1974) and their instability in aqueous solution especially at low $\mathrm{pH}$ (Adeleye 1995). Recently, chemically modified pillared clays prepared in the presence of long chain organic molecules were found to adsorb organic toxicants and inorganic metal ions from aqueous effluents. Specificity of adsorption was dependent on the chain length of the molecule (Sakai et al 1987, 1993). On recyclability by combustion, the pillared clays retained most of their ability to adsorb (Zielke and Pinnavaia 1988). Clays treated with the alkylammonium ion and hexadecylpyridinium, were found to adsorb radioiodine; in the absence of treatment high mobility of the nuclide was observed (Bors 1988, 1992, 1997). Hence iodine adsorption at clay-water interface has an important bearing on the fate and transport of iodine in the aqueous natural environment.

The easy surface modification by surfactants has prompted us to make use of this technique to design a recyclable clay adsorbent for iodine in aqueous medium. Since clay particles are themselves charged, ionic surfactants would bring about coagulation of the particles

*Author for correspondence thus decreasing their adsorption characteristics. Non-ionic surfactants, hence, are preferred. Further, modification of surface greatly enhances the intake of adsorbate molecules and equilibrium condition will be attained rapidly. In this paper we have made an attempt to increase the adsorption of iodine by modifying the clay surface and explain the adsorption with the help of Freundlich and Scatchard adsorption isotherms. These parameters provide better knowledge of the adsorption behaviour and valuable information regarding affinity, binding strength and number of types of binding sites involved in the adsorption process which help to design a recyclable adsorbent.

\section{Experimental}

The clay mineral used in this study was a swelling type smectite rich clay from Bhuj area, Gujarat (supplied by Ashapura Chemicals) containing essentially montmorillonite. It was fractionated using dispex as the dispersant to collect less than $2 \mu \mathrm{m}$ fraction. The clay sample was characterized by XRD and XRF and found to be rich in montmorillonite. The idealized formula was found to be $\left(\mathrm{Si}_{7.99} \mathrm{Al}_{0.01}\right)\left(\mathrm{Al}_{2.4} \mathrm{Mg}_{0.75} \mathrm{Fe}_{0.4} \mathrm{Ca}_{0.45}\right) \mathrm{Na}_{0.6} \mathrm{~K}_{0.15}$. The cation exchange capacity (CEC) was found to be in the range $0.73 \mathrm{meq} / \mathrm{g}$.

\subsection{Preparation of modified clay}

Two types of nonionic surfactants were selected: (i) tween-80 (polyoxyethylene sorbitan monooleate, SD Fine 
Chemicals) having three different types of functional groups-ethylene oxide, sorbitan and oleic- and (ii) PEG-300 (polyethylene glycol, SD Fine Chemicals) possessing only one type of functional group i.e. ethylene oxide. Known amounts of the surfactants were dissolved separately in $20 \mathrm{ml}$ of water to which $1 \mathrm{~g}$ of clay was added to each and mixed thoroughly in wrist-action shaker for $30 \mathrm{~min}$. The mixture was centrifuged and the centrifugate was discarded. The solid was washed two times with double distilled water to remove superficially held adsorbate. The amount of surfactant adsorbed was determined by carbon-hydrogen analysis using Carlo Erba CHN-analyzer Instrument. The amount of surfactant adsorbed increased with the concentration of the adsorbate and attained saturation. The modified clays were used for all the adsorption studies.

\subsection{Iodine adsorption}

One $\mathrm{g}$ of modified clay was added to different concentrations of iodine (SD Fine Chemicals) solution $(60 \mathrm{ml})$ and the mixture was shaken for $30 \mathrm{~min}$ and centrifuged. The iodine present in the centrifugate was determined colorimetrically using crystal violet (Rand et al 1975). All the trials were accompanied by blank containing only iodine solution. The difference was taken as the amount of iodine adsorbed. The adsorption was also determined at different $\mathrm{pH}$ values adjusted using hydrochloric acid and sodium hydroxide. The clays were

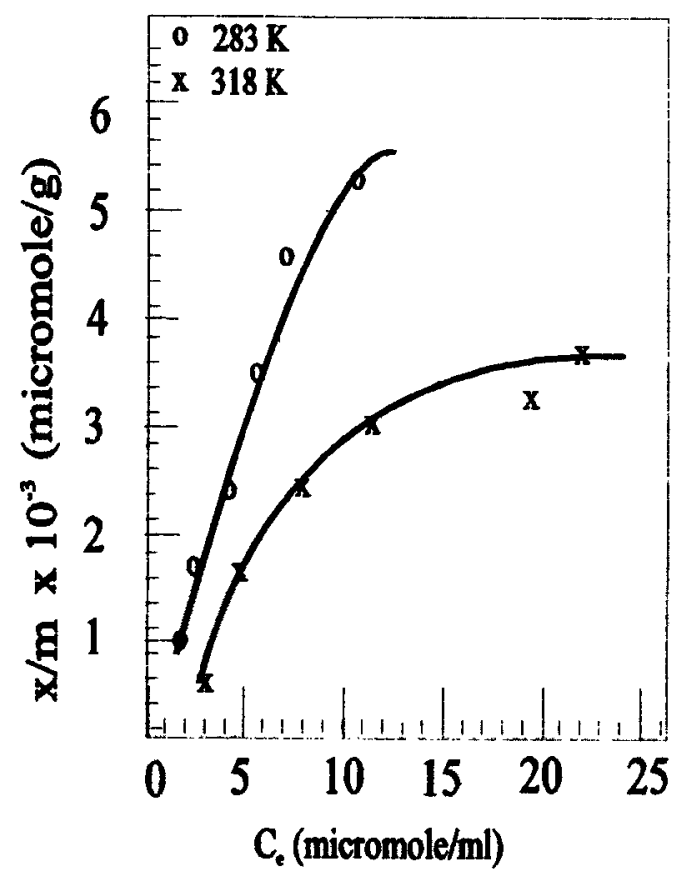

Figure 1. Langmuir plots of iodine adsorption on tween-80 modified clay. washed with water to desorb iodine and the recyclability for adsorption of iodine was also examined.

\section{Results and discussion}

The amount of iodine adsorbed on the modified surface was found to be very much higher $(\approx 550 \mathrm{mg} / \mathrm{g})$ compared with that on unmodified surface $(<70 \mathrm{mg} / \mathrm{g})$. The adsorption of iodine on modified clay surface in the $\mathrm{pH}$ range 1-10 was found to be constant. A typical adsorption isotherm plot, $x / m$ against $C e$, where $x / m$ is the amount of iodine adsorbed per $g$ of modified/unmodified clay and $\mathrm{Ce}$, the equilibrium concentration is shown in figure 1 (at $283 \mathrm{~K}$ and $318 \mathrm{~K}$ ). The adsorption of surfactant on the unmodified clay surface and iodine on the modified surface in the concentration range studied were found to fit the Freundlich equation expressed in the linear form,

$$
\log x / m=k+l / n \log C e,
$$

where constants $k$ (intercept) and $l / n$ (slope), the latter being less than unity, provide rough estimates of the adsorbent capacity to sorb the adsorbate strongly and a qualitative picture of the homogeneity of the surface, respectively (Adamson 1987). Figure 2 shows the Freundlich adsorption isotherm for the adsorption of iodine on unmodified clay. The adsorption was found to be very weak $\left(k=1.38 \times 10^{-3}\right.$ at $298 \mathrm{~K}$, table 1$)$. The isotherms for surfactant adsorption on unmodified surface

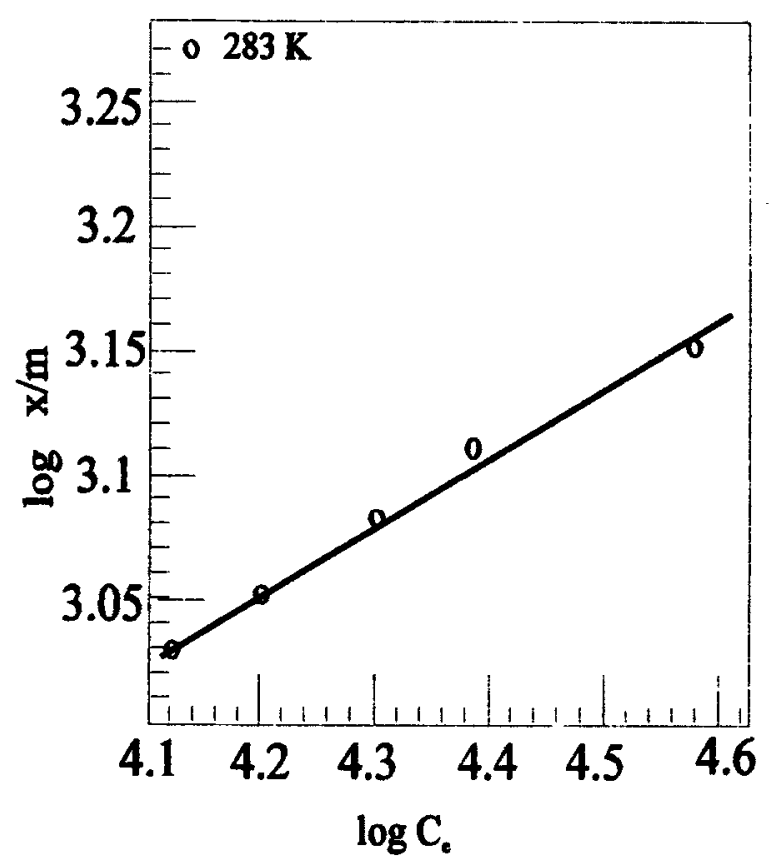

Figure 2. Freundlich plots of iodine adsorption on unmodified clay. 
are shown in figures 3 and 5 for twen-80 and PEG-300, respectively. Figures 4 and 6 show the Freundlich adsorption isotherm for iodine adsorption on the modified clays. Table 1 gives $k$ and $l / n$ values for the adsorption of surfactant on unmodified clay surface and iodine adsorption on the modified surface.

\subsection{Freundlich adsorption data}

3.1a Adsorption of surfactants: Adsorption of tween-80 increases from $283 \mathrm{~K}$ to $318 \mathrm{~K}$ (figure 3 ). This shows

Table 1. Freundlich constants of surfactant and iodine adsorption on unmodified and moditied clays.

\begin{tabular}{lccc}
\hline & $\begin{array}{c}\text { Temperature } \\
\text { Sample }\end{array}$ & $k$ & $l / n$ \\
\hline $\begin{array}{l}\text { Iodine on unmodified } \\
\text { clay }\end{array}$ & 298 & $1.38 \times 10^{-3}$ & 0.34 \\
$\begin{array}{l}\text { Tween-80 on unmodi- } \\
\text { fied clay }\end{array}$ & 283 & $4.07 \times 10^{-1}$ & 0.18 \\
$\begin{array}{l}\text { lodine on modified } \\
\text { clay with tween-80 }\end{array}$ & 318 & $6.92 \times 10^{-1}$ & 0.24 \\
$\begin{array}{l}\text { PEG-300 on unmodi- } \\
\text { fied clay }\end{array}$ & 283 & $1.32 \times 10^{-2}$ & 0.88 \\
$\begin{array}{l}\text { Iodine on modified } \\
\text { clay with PEG-300 }\end{array}$ & 283 & $5.80 \times 10^{-3}$ & 0.75 \\
& 318 & $1.43 \times 10^{-3}$ & 0.76 \\
\hline
\end{tabular}

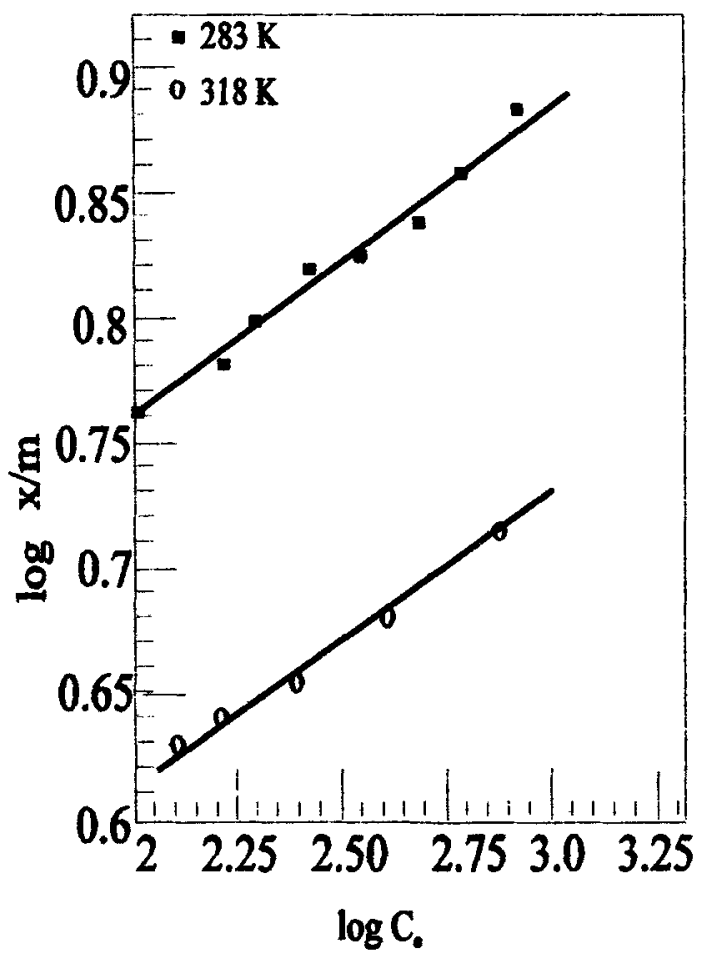

Figure 3. Freundlich plots of tween-80 adsorption on unmodified clay. that tween- 80 has a tendency to chemisorb on the clay surface whereas the results show a physisorption for PEG-300 (figure 5). This is supported by the heat of adsorption results $\left(\Delta H=-63.0 \mathrm{~kJ} \mathrm{~mol}^{-1}\right.$ for tween-80 adsorption and $\Delta H=-8.5 \mathrm{~kJ} \mathrm{~mol}^{-1}$ for PEG-300 adsorption). This may be because of the presence of oleic (hydrophobic) group in the molecule of tween-80. The montmorillonite clay surface used in this study behaves more hydrophobic and hence holds tween-80 more strongly than PEG-300. The latter has a long hydrophilic chain of ethylene oxide groups which explains its weak adsorption.

3.1b Adsorption of iodine: The value of $k$ for the adsorption of iodine on bare clay surface, as shown in table 1 , is found to be lower $\left(1.38 \times 10^{-3}\right)$ than those on the modified surface. This shows that iodine is adsorbed more strongly on the modified surface. Higher value of $k$ for the adsorption of iodine on tween-80 modified surface $\left(1.32 \times 10^{-2}\right)$ shows that the tween-80 molecule provides stronger sites of adsorption for iodine than PEG-300 $\left(1.43 \times 10^{-3}\right)$. The constant $l / n$ gives a qualitative picture of surface homogeneity (Comans and Hockley 1992; Siobhan and Roubaud 1997); higher the value of $l / n$ higher is the surface homogeneity.

\subsection{Scatchard adsorption constants}

The Scatchard adsorption constant was considered useful for determining whether the adsorption occurred at the same type of sites or different types of sites were

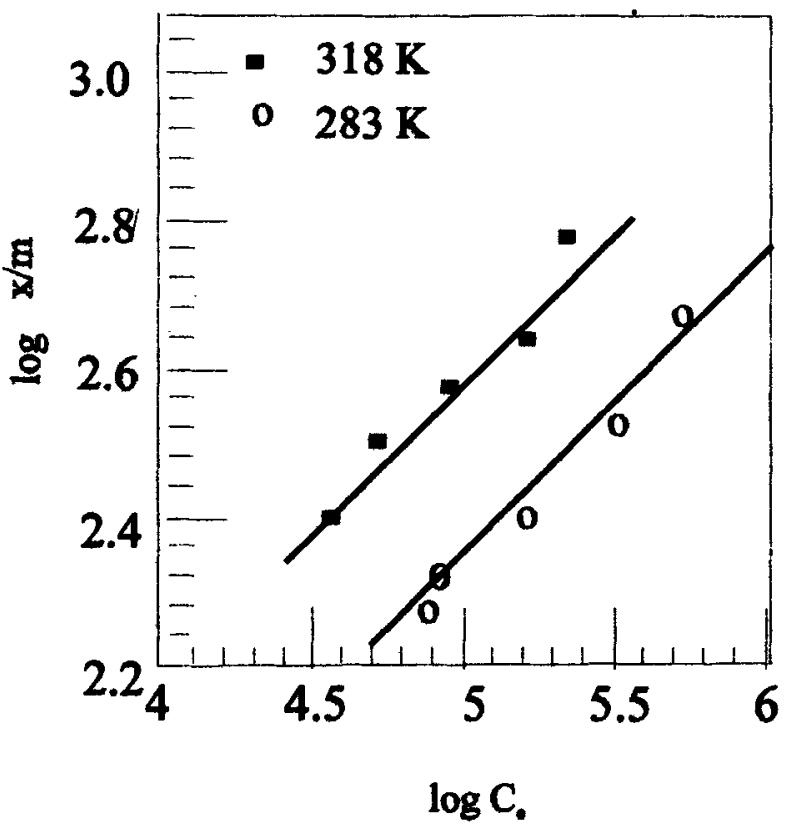

Figure 4. Freundlich plots of iodine adsorption on tween-80 modified clay. 
involved in any case. The adsorption data were fitted to the Scatchard (1949) equation in its simplest and most utilized form (Narine and Guy 1982):

$$
X / C_{\mathrm{e}}=k_{\mathrm{s}} n_{\mathrm{s}}-k_{\mathrm{s}} X,
$$

where $X$ is the amount of adsorbate adsorbed per $g$ of the adsorbent (micromole/g), $C_{\mathrm{e}}$ the equilibrium concentration (micromole/ml), $k_{\mathrm{s}}$ (slope) and $n_{\mathrm{s}}$ (intercept) are Scatchard constants. Scatchard plot gives a measure of

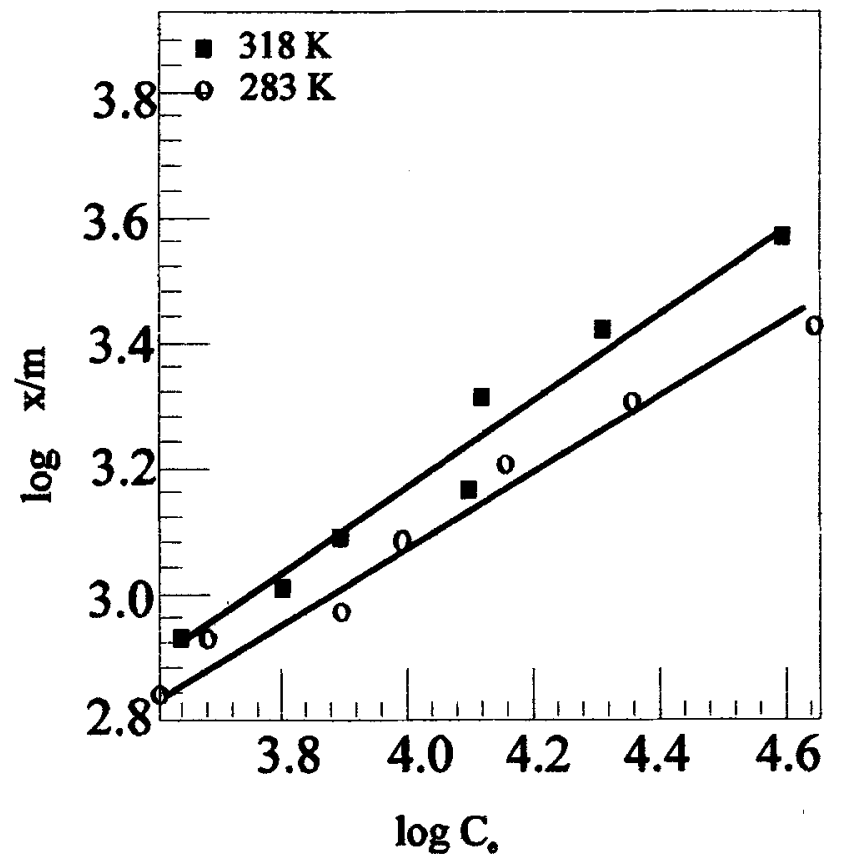

Figure 5. Freundlich plots of PEG-300 adsorption on unmodified clay.

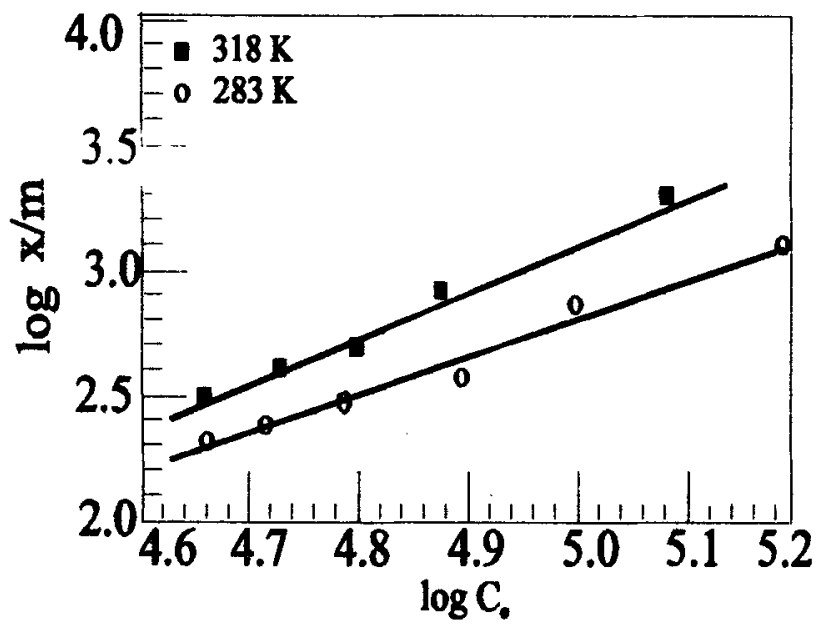

Figure 6. Freundlich plots of iodine adsorption on PEG-300 modified clay. the fraction of adsorbate retained on the solid at different adsorbate concentrations. A steep decrease in the fraction adsorbed (a higher slope of the isotherm line) would indicate a more active site and conversely a line with lower gradient would indicate a lesser active site. Thus breaks in the Scatchard plot show a non-homogeneous surface with different stability constants.

Scatchard plots of the adsorption of surfactant on unmodified clay and iodine adsorption on modified surface are presented in figures 7 to 11 and table 2 gives the Scatchard constants. Adsorption of jodine on the unmodified surface (figure 7) shows two regions of adsorption on the bare surface of montmorillonite. Region I shows stronger sites $\left(k_{\mathrm{s}}=3.43 \times 10^{-1}\right)$ than region II $\left(k_{\mathrm{s}}=6.78 \times 10^{-2}\right)$, the former perhaps representing the adsorption on the edge sites (Lockhart 1981).

Adsorption of tween-80 on the clay surface (figure 8) also shows two clear regions of adsorption, region I being very strong and apparently indicates the adsorption at the interlamellar regions. Surfactants are known to intercalate in montmorillonite (Desbene 1997). The strong site of adsorption is indicated by a high value of $k_{\mathrm{s}}$ $(16.2$ at $283 \mathrm{~K}$ in region $\mathrm{I}$, table 2) supporting the chemisorption of tween-80.

Figure 9 shows the adsorption of iodine on clay surface modified by tween-80-three regions of adsorption are indicated. Region I shows stronger sites of adsorption $\left(k_{\mathrm{s}}=2.6 \times 10^{-1}\right.$ at $\left.283 \mathrm{~K}\right)$ than region II $\left(k_{\mathrm{s}}=7.4 \times 10^{-2}\right.$ at $283 \mathrm{~K}$ ). The structure of tween- 80 , polyoxyethylene sorbitan monooleate, consists of three moieties-hydrophilic ethylene oxide chains, sorbitan and a hydrophobic oleic group. The strong adsorption of iodine on oleic

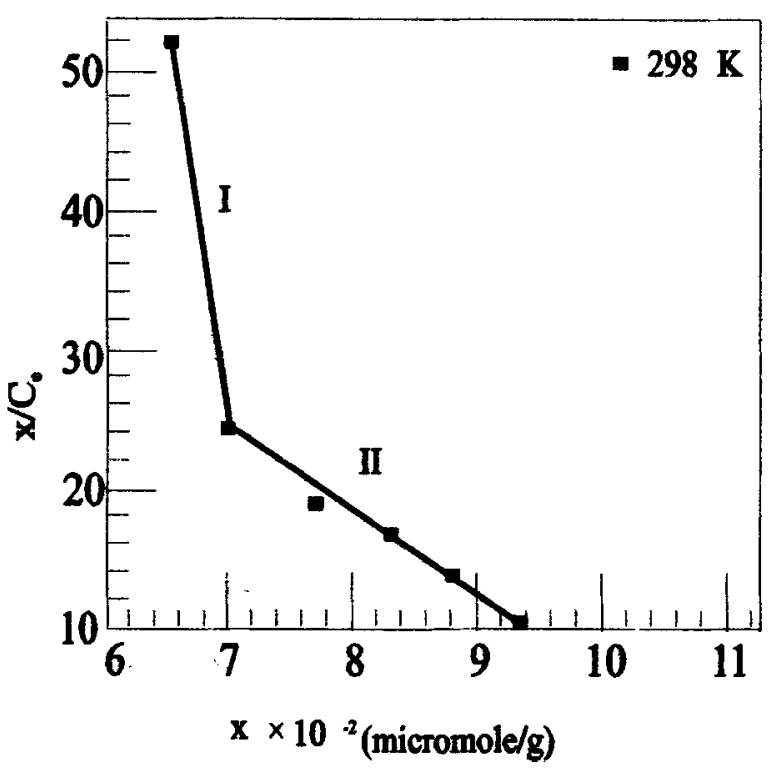

Figure 7. Scatchard plots of iodine adsorption on unmodified clay. 


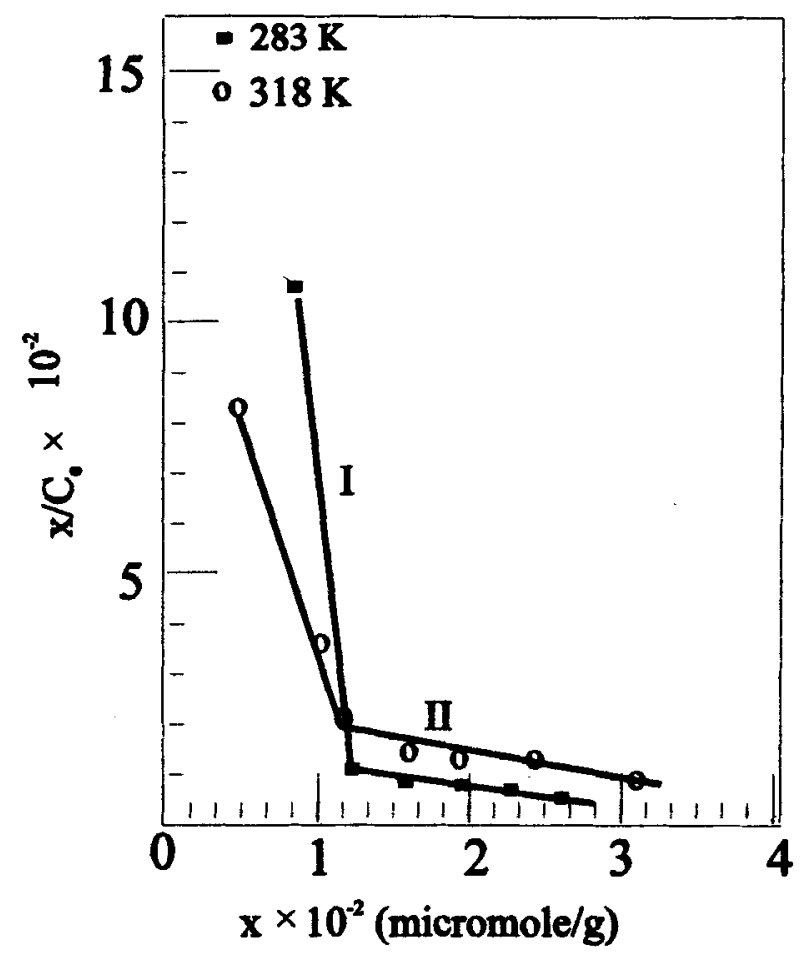

Figure 8. Scatchard plots of tween-80 adsorption on unmodified clay.

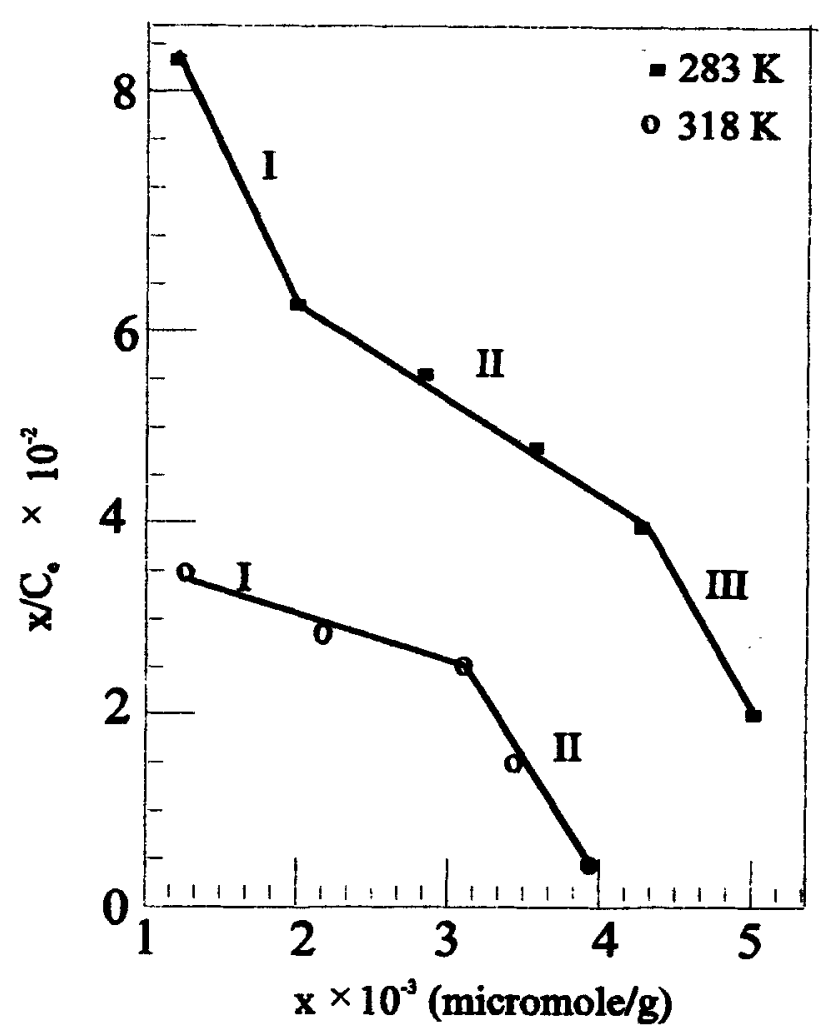

Figure 9. Scatchard plots of iodine adsorption on tween-80 modified clay. group (confirmed by a separate experiment) apparently is responsible for region I and the ethylene oxide groups for region II on the adsorption isotherm (figure 9 at $283 \mathrm{~K}$ ). Region III, however, is stronger than region II as indicated by higher $k_{\mathrm{s}}$ value $\left(4.0 \times 10^{-1}\right.$ at $\left.283 \mathrm{~K}\right)$. Adsorption of iodine at region III at $283 \mathrm{~K}$ is thus due to the adsorbate-adsorbate interaction that takes place once the surface is saturated and is stronger than adsorption over polyoxyethylene sites. Presence of only two regions at $318 \mathrm{~K}$ (figure 9) shows the absence of adsorption of iodine due to polyoxyethylene groups because weak physical adsorption are not seen at higher temperatures. (Region II in figure 9 at $318 \mathrm{~K}$ may thus be the region III observed at $283 \mathrm{~K}$ ). The value of $n_{\mathrm{s}}$ (table 2) is an indication of the number of sites of adsorption which shows that the number is higher in region II (polyoxyethylene groups) than in region I (oleic group). However, the number of binding sites as determined by the intercept gives a very qualitative picture of the number. Our main interest in applying the Scatchard equation was to identify the type of sites and the nature of binding process.

Scatchard plot of adsorption of PEG-300 on clay surface (figure 10) shows two regions similar to tween -80 adsorption. The sites are much weaker $\left(k_{\mathrm{s}}=2.78 \times 10^{-2}\right.$

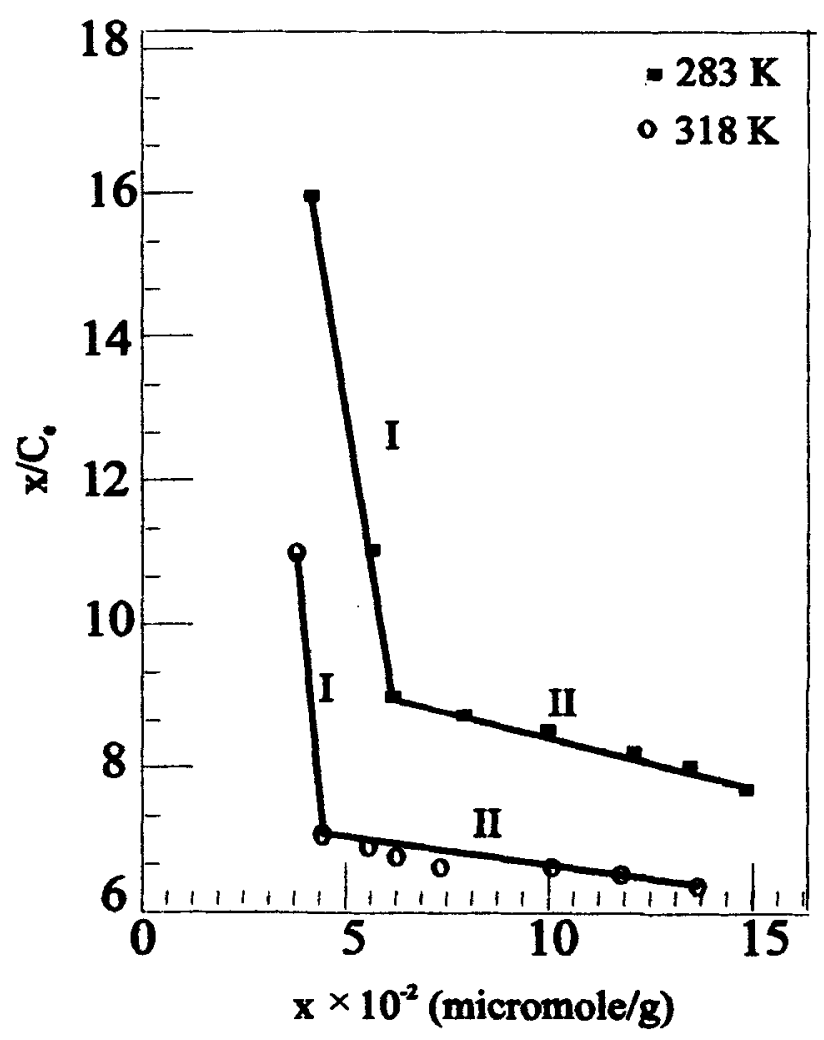

Figure 10. Scatchard plots of PEG-300 adsorption on unmodified clay. 
at $283 \mathrm{~K}$ in region $\mathrm{I}$, table 2) and the adsorption is physical as indicated by the heat of adsorption $\left(\Delta H=-8.5 \mathrm{~kJ} \mathrm{~mol}^{-1}\right)$. However, iodine adsorption on clay surface modified with PEG-300 shows only one region (figure 11) due to the fact that it has only polyoxyethylene chain. Absence of adsorbate-adsorbate interaction is attributed to small coverage of the surface by iodine on PEG-300 without leading to saturation.

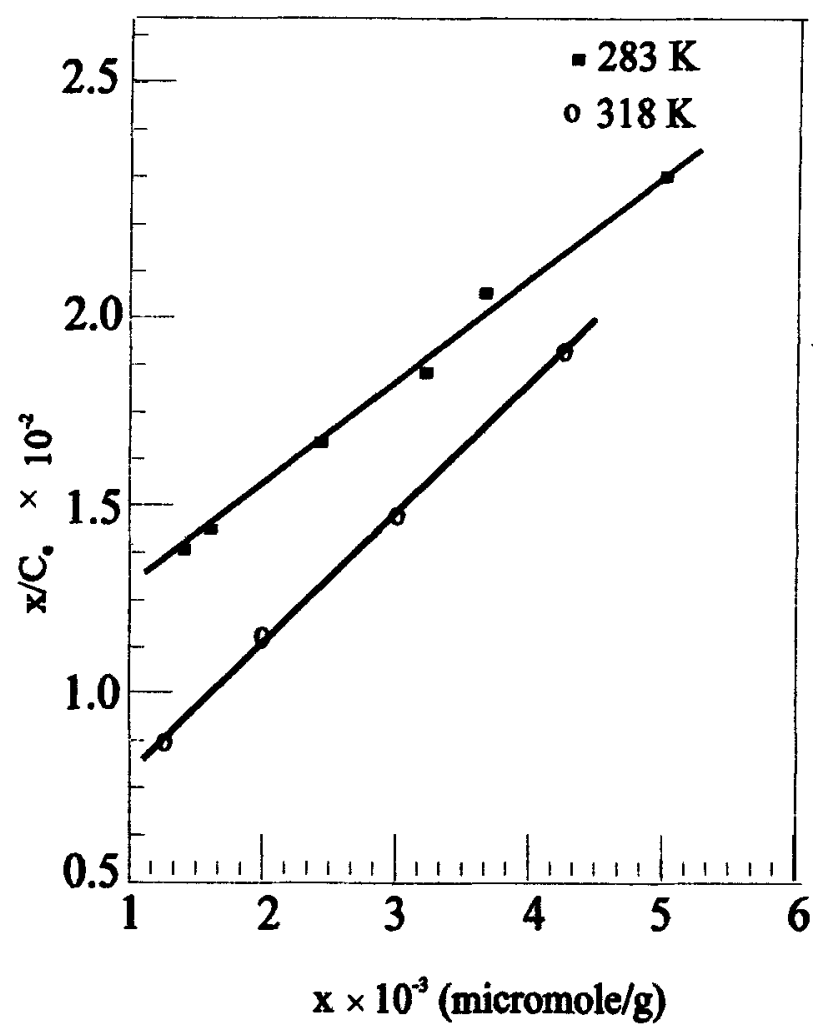

Figure 11. Scatchard plots of iodine adsorption on PEG-300 modified clay.

\subsection{Recyclability of the surface}

Washing the modified clay with deionized water for desorbing the iodine present showed that all the iodine $(>95 \%)$ in the elemental form could be recovered by washing. The iodine was found to desorb very gradually in the case of tween- 80 modified clay than in the PEG-300 modified one, once again corroborating the strong adsorption of iodine in the former case than in the latter. Large number of washings were needed to remove the last traces of iodine in the case of tween- 80 modified clay. This is perhaps the iodine adsorbed on the oleic group. After desorption the modified clays were found to adsorb almost the same amounts of iodine repeatedly. Loss of surfactant from the surface after repeated washing was found to be negligible. Thus chemical modification offers a method for preparing a recyclable adsorbent for iodine.

\section{Conclusions}

Iodine adsorption on chemically modified clays was found to increase considerably upon modification of the montmorillonite clay surface with surfactants such as tween- 80 and polyethylene glycol. The adsorption data were found to follow the Freundlich equation in the concentration range studied. Tween- 80 was found to chemisorb $\left(\Delta H=-63.0 \mathrm{~kJ} \mathrm{~mol}^{-1}\right)$ on the clay surface while PEG-300 exhibited a physical adsorption. Iodine was found to get adsorbed on the modified surface through physical adsorption which could be completely recovered in the elemental form by simple washing. Scatchard analysis showed that iodine adsorbed on three regions in the case of tween-80 modified clay but on only one region in the case of PEG-300 treated clay. Test for recyclability showed that the modified clays could be used several times for adsorbing iodine without any loss of surfactant. Thus chemical modification offers

Table 2. Scatchard constants for surfactant and iodine adsorption on unmodified and modified clays.

\begin{tabular}{|c|c|c|c|c|c|c|c|}
\hline \multirow[b]{2}{*}{ Sample } & \multirow{2}{*}{$\begin{array}{l}\text { Temperature } \\
(\mathrm{K})\end{array}$} & \multicolumn{2}{|c|}{ Region-I } & \multicolumn{2}{|c|}{ Region-II } & \multicolumn{2}{|c|}{ Region- III } \\
\hline & & $k_{\mathrm{s}}$ & $n_{\mathrm{s}}$ & $k_{\mathrm{s}}$ & $n_{s}$ & $k_{\mathrm{s}}$ & $n_{\mathrm{s}}$ \\
\hline Iodine on unmodified clay & 298 & $3.43 \times 10^{-1}$ & 184 & $6.78 \times 10^{-2}$ & 442 & - & - \\
\hline $\begin{array}{l}\text { Tween- } 80 \text { on unmodified } \\
\text { clay }\end{array}$ & $\begin{array}{l}283 \\
318\end{array}$ & $\begin{array}{r}16 \cdot 2 \\
7 \cdot 7\end{array}$ & $\begin{array}{l}31 \\
51\end{array}$ & $\begin{array}{l}0.17 \\
0.35\end{array}$ & $\begin{array}{l}253 \\
285\end{array}$ & - & - \\
\hline $\begin{array}{l}\text { Iodine on modified clay } \\
\text { with tween- } 80\end{array}$ & $\begin{array}{l}283 \\
318\end{array}$ & $\begin{array}{l}2.6 \times 10^{-1} \\
1.4 \times 10^{-1}\end{array}$ & $\begin{array}{l}4,436 \\
5,147\end{array}$ & $\begin{array}{c}7.4 \times 10^{-2} \\
-\end{array}$ & $\begin{array}{c}10,284 \\
-\end{array}$ & $\begin{array}{l}4.0 \times 10^{-1} \\
4.2 \times 10^{-2}\end{array}$ & $\begin{array}{l}5,500 \\
8,983\end{array}$ \\
\hline $\begin{array}{l}\text { PEG-300 on unmodified } \\
\text { clay }\end{array}$ & $\begin{array}{l}283 \\
318\end{array}$ & $\begin{array}{l}2.78 \times 10^{-2} \\
4.55 \times 10^{-2}\end{array}$ & $\begin{array}{r}1,666 \\
761\end{array}$ & $\begin{array}{l}1.5 \times 10^{-3} \\
5.0 \times 10^{-4}\end{array}$ & $\begin{array}{r}6,666 \\
14,400\end{array}$ & - & - \\
\hline $\begin{array}{l}\text { Iodine on modified clay } \\
\text { with PEG-300 }\end{array}$ & $\begin{array}{l}283 \\
318\end{array}$ & $\begin{array}{r}2.3 \times 10^{-2} \\
2.74 \times 10^{-2}\end{array}$ & $\begin{array}{l}4,500 \\
2,190\end{array}$ & - & - & - & - \\
\hline
\end{tabular}


a method of preparing recyclable adsorbents for iodine adsorption.

\section{Acknowledgements}

The authors wish to acknowledge with thanks financial assistance from the Department of Atomic Energy, Government of India, for carrying out this project. The authors are grateful to Prof. B K Sadashiva, Raman Research Institute, Bangalore for carbon analysis measurements. Grateful thanks are also due to the Principal and the members of the Governing Council of Bangalore Institute of Technology, for the facilities provided.

\section{References}

Adeleye S A 1995 J. Mater. Sci. 30583
Adamson A 1987 Physical chemistry of surfaces and interface science (New York: Publishers Inc.)

Bors J 1988 Radiochimica Acta 44/45 201

Bors J 1992 Radiochimica Acta 58/59 235

Bors J 1997 Clay Miner. 3221

Comans R-N J and Hockley D E 1992 Geochim. Cosmochim. Acta $56 \quad 1157$

Desbene P L 1997 J. Colloid \& Interface Sci. 190350

Lockhart N C 1981 Clays \& Clay Miner. 29413

Mortland M M 1970 Adv. Agron. 2275

Mortland M M 1986 Clays \& Clay Miner. 34581

Narine R and Guy R D 1982 Soil Sci. 133356

Rand M S et al 1975 Standard methods for the examination of water and waste water (New York: American Public Health Association) 16th ed., p. 397

Sakai Y et al 1987 Bull. Chem. Soc. Jpn 60545

Sakai Y et al 1993 Bull. Chem. Soc. Jpn 663107

Siobhan S and Roubaud M 1997 Clays \& Clay Miner. 45251

Theng B K G 1974 The chemistry of clay organic reactions (London: Hilger)

Zielke R G and Pinnavaia T J 1988 Clays \& Clay Miner. 36403 